\title{
El corazón de las tinieblas
}

\author{
Sagrario AZnAR AlmaZÁN \\ UNED
}

Contradicción tras contradicción, el siglo XIX, el Romanticismo básicamente, fue abriendo camino a nuevos modos, nuevas formas y nuevos sentimientos. De hecho, gracias a su casi oposición radical al Clasicismo, al menos de un modo superficial y, desde luego, mucho más clara en el Romanticismo tardío, va a surgir la categoría estética de modernidad, difusa pero absolutamente fundamental para comprender el arte y la actitud de los artistas hasta nuestros días.

De hecho, las raíces comunes de la nueva sensibilidad y del nuevo arte al que dará lugar el Romanticismo se desarrollan, por un lado, en la desconfianza, entre escéptica y dramática, hacia su época, pero por otro, en el cultivo de un individualismo cada vez más serio, más trágico y más radical. Como ha señalado Rafael Argullol ${ }^{1}$, frente a la absurda identificación del Romanticismo como una simple "evocación del pasado" y a su desdichada distinción académica con respecto a lo clásico, la reflexión romántica es, sobre todo, una concepción trágica del hombre y del mundo modernos.

Es conocido el hecho de que Kirkegaad deseaba para su epitafio una inscripción tan breve como "Fue el individuo». Así lo dejó escrito en una nota correspondiente a 1847. La importancia del individualismo, el resurgimiento del Yo en el Romanticismo, implica, sobre todo, la recuperación de una idea renacentista del hombre, según la cual éste era unidad al mismo tiempo de poder y de impotencia, de conocimiento y de enigma de subjetividad. Una unidad, en fin, capaz de negar tanto el trascendentalismo antihumanista (que suscitaron la Contrarreforma católica y buena parte de

1 ARgullol, R., El Héroe y el Único. El espiritu trágico del Romanticismo, Barcelona, Destino, 1990, p. 12. 
la Reforma protestante) como el «Imperium hominis» con que Bacon alentó el Empirismo y la llustración. Una unidad, como señala de nuevo Argullol ${ }^{2}$, que rechaza al hombre como mendigo y al hombre como dios pues a ambos acepta en cuanto proclama que "el hombre es un dios cuando sueña y un mendigo cuando reflexiona" (Hölderlin).

Bajo estos presupuestos es lógico que la mayor parte de los románticos no se molesten en disimular en absoluto su abierta rebelión contra el hombre científico, contra el hombre newtoniano. «Malditas sean las matemáticas!», gritan John Keats y Charles Lamb en su famoso brindis tabernario contra Newton, al que acusaron nada menos que de haber destruido la poesía del arco iris. "¿Por qué devoras el corazón del poeta, oh buitre, cuyas alas son sórdidas realidades?", pregunta Edgar Allan Poe en su soneto To Science. A los románticos, es obvio, les resulta inaceptable, la mecánica pasividad del «hombre newtoniano", sujeto receptivo de un «un haz de diferentes percepciones que se suceden con inconcebible rapidez, en un flujo y un movimiento perpetuo" (Hume), y aniquilado por ello precisamente bajo el peso de su propio poder: es el mendigo que ha creído poder llegar a ser dios mediante la reflexión pero que, al renunciar al sueño, se ha reducido a sí mismo al triste estado de mendigo. De este modo, bajo el brillante ropaje del optimismo ilustrado y del progreso empirista, los románticos no dejan pasar inadvertida la minimización a que se ha visto irremediablemente sometido el hombre moderno: al correr el prudente velo que ocultaba la tiránica grandeza de la naturaleza, él mismo se ha empequeñecido. Si además es incapaz de descubrir la propia grandeza de su subjetividad, el empequeñecimiento se hará sentir doblemente y a la gran «Edad de la Razón» seguirá la angustia de la razón. La única salida es el redescubrimiento de la subjetividad, el viaje al interior del hombre, al «Corazón de las Tinieblas». Un viaje que, lleno de contradicciones y a través de un hombre brutalmente escindido, todavía no ha terminado en este final del siglo $x x$.

La manía de la autobservación, e incluso de la autoadmiración en el arte, y la idea de que una obra es tanto más verdadera y convincente cuanto más directamente se refleja el autor en ella, forman parte, en realidad, de la herencia espiritual de Rousseau. Antes de él, el artista hablaba de sí mismo sólo de un modo indirecto. Después de él, apenas habla de otra cosa y lo hace de la manera más descarada. Desde entonces, todo lo que tiene alguna significación en la cultura occidental no tendrá

2 Afgullol, R., Op. cit., 1990, p. 14. 
más remedio que estar bajo el signo de este subjetivismo. Un subjetivismo que encuentra vigencia total por primera vez en el Werther de un Goethe capaz de declarar de sus obras que todas ellas no eran otra cosa que "fragmentos de una gran confesión".

$Y$ a su vez este «imperio de lo subjetivo", que conlleva también una renovada búsqueda de Paraisos Perdidos que pueden perfectamente acabar siendo Artificiales, supone un paso revolucionario hacia la cada vez más difusa idea de modernidad. Como ha señalado Francisco Calvo Serraller ${ }^{3}$, desde el poder de lo subjetivo, la verdad y la expresión pueden transformarlo todo, porque son capaces de edificar mundos a la medida de quienes los están creando. Lo subjetivo se pone a sí mismo, pero jamás se impone, como un valor socialmente edificante, sea moral o estético; como algo ejemplar, trascendente y objetivo. Es decir, lo subjetivo se expresa simplemente y todo el arte moderno acabará discurriendo por esta ilusión sin retorno del yo creador. Porque el horizonte de las efusiones artísticas subjetivas por de pronto no tiene límites. De entrada no tiene las barreras clásicas de la imitación selectiva de la realidad. En el arte moderno no hay objetos que imitar, sino sujetos que se expresan de manera que el contenido resulta imprevisible y la forma se hace autónoma. Mientras el arte clásico halla su razón de ser en la imposición de límites, el arte moderno fijará su identidad en la capacidad de burlarlos.

Pero aún hay más. En este paso revolucionario de una concepción artística objetiva a otra subjetiva que es, hemos visto, el paso que se da desde el arte clásico al moderno, hay otro hecho decisivo: la temporalización de la belleza, también señalada por Calvo Serraller. La belleza clásica es trascendente y eterna; la moderna será inmanente y temporal. El arte clásico depende de una realidad exterior más o menos idealizada; el arte moderno, única y exclusivamente de una ilusión interior. La puerta del frenético siglo $x x$ queda así claramente abierta.

En realidad, esta idea obsesiva que llega a ser el impulso a la introspección, la autobservación casi maniática, no es otra cosa que un nuevo intento de fuga, expresando una vez más la incapacidad del Romanticismo para contentarse con su propia situación histórica y social. Esta fuga de una realidad que el hombre ha demostrado ser incapaz de dominar por medios racionales conlleva una posible solución irracional para sus problemas. Porque lo irracional tiene la ventaja de no estar sujeto a ningún dominio consciente y es posible que encuentre en ella la satisfacción que

3 Calvo Serraller, F., La novela del artista, Madrid, Mondadori, 1990. 
no puede darle el intelecto seco y frío. De hecho, los románticos nunca llegaron a renunciar al mito de la «Edad de Oro», una edad, considerada atemporal, en que verdad, belleza y naturaleza formaban un todo único y orgánico al que el hombre podía acceder. Precisamente parece que una de las causas fundamentales de la irremediable desolación romántica, violentamente perceptible en Leopardi, por ejemplo, es la cada vez más evidente imposibilidad de acceder a esa unidad, a esa reconciliación, a ese restablecimiento. En este sentido, Hegel fue, probablemente, el más claro de todos: hay que reconocer el mundo como es o perecer porque ninguna idea o proyecto genérico pueden seguir pretendiendo dar su norma a la realidad, ningún ideal, clásico o no, pero mucho menos clásico, puede suspender el tiempo. Existen, desde luego, Edades de Oro y Paraísos Perdidos a los que el hombre romántico desearía acceder angustiosamente, pero es en la imposibilidad de ver cumplido ese deseo donde reside su aniquilación. El individuo romántico llega a darse cuenta de que es un camino imposible, un camino sin retorno que acabará impregnando de una cierta nostalgia a toda la época. Pronto notará que los Paraísos Artificiales son sólo un débil sustituto. La única posibilidad de salvación es, de nuevo, el viaje al interior, en una peligrosa búsqueda de identidad. Como dicen las "Lecciones hegelianas de Estética", al bello cuerpo griego, lleno de espíritu, le faltó la profundidad subjetiva del recuerdo; el Romanticismo, a su vez, despreciando la representatividad, puede llevar el arte a la destrucción, más allá de sus límites, pero a la vez puede provocar el único camino ahora posible: el retorno, el "descenso" del hombre a su interior.

Los románticos convierten asi la creación artística en un proceso misterioso. Tanto para el Clasicismo cortesano como para la llustración había sido simplemente una actividad intelectual definible con claridad y apoyada en unas reglas de gusto que podían explicarse y podían aprenderse con mayor o menor dificultad. Las Academias, como centros docentes, tenían entonces un sentido que ahora irán perdiendo. Difícilmente se puede reglamentar, y mucho menos enseñar, un arte que surge de fuentes tan insondables como la inspiración divina, la intuición ciega y una incaculable disposición de ánimo.

Sólo el genio, tal y como el Romanticismo lo entiende, es capaz de estar inmerso en un proceso tan inexplicable como complicado. Que saque o no algo en limpio de todo eso es lo que menos importa a los románticos porque no interesa tanto la obra acabada como el sentimental, pasional y frenético estado artístico que la precede. De hecho, para el Clasicismo y la Ilustración el genio era una inteligencia esclarecida vinculada a la razón, la teoría, la historia, la tradición y los convencionalismos; para el Romanticis- 
mo, sin embargo, se irá convirtiendo poco a poco en un ideal. Un ideal para el que es, sobre todo, decisiva precisamente la falta de estos vínculos porque sólo es capaz de redimirse de las miserias cotidianas que tanto le agobian en la tierra imaginaria del libre albedrío sin restricciones. En ella se sentirá libre de las cadenas de la razón y al mismo tiempo estará en posesión de unas fuerzas místicas que harán innecesaria para él la experiencia sensible ordinaria. "El genio tiene presentimientos; es decir, su sentimiento va por delante de su observación. El genio no observa. Ve, siente», dice Lavater. El genio se irá convirtiendo así, muy ayudado por Nietzsche ${ }^{4}$, en un titán rebelde, sobrehumano y semejante a Dios, en el guardián de una sabiduría misteriosa, legislador de un mundo propio con leyes propias.

Por este camino, muy pronto empezarían los románticos a reclamar derechos tan conflictivos como la capacidad de seguir su propia inspiración sin ayudas ni estorbos, y la posibilidad de desarrollar su sensibilidad individual expresando sus sentimientos más íntimos sin respetar las reglas teóricas o las conveniencias sociales. Y es más, con frecuencia, desafiándolas.

El concepto de "artista» como "maestro en un arte, por lo común en un arte manual", que había tenido vigencia hasta el siglo XVIII, se halla ahora diametralmente alejado de lo que tenía en mente Friedrich Schlegel cuando señalaba, sin dudarlo ni por un momento, que los artistas eran el resto de la humanidad lo que los seres humanos al resto de la creación ${ }^{5}$. Los artistas comenzaban a considerarse personas aparte (en cierto modo a automarginarse), un poco como los "elegidos" calvinistas o como los supuestos «sacerdotes» que había explicado Saint-Simón ${ }^{6}$. "Fui un elegido.

4 Nietzsche en Asi habló Zaratustra llega a identificar, prácticamente al principio del libro, a su superhombre con el genio artístico, entendido como un ser humano capaz de liberarse de todos los prejuicios (históricos, sociales, morales...) para crear un mundo propio y mejor que además enseñará a vivir a los demás hombres.

5 Algo que se puede perfectamente poner en paralelo con la comparación que hace Nietzsche del superhombre al decir que el superhombre es al hombre lo mismo que éste es a los animales.

- Hacia el final de su vida uno de los principales intereses de Saint-Simon había sido el relativo a los aspectos espirituales y religiosos del hombre y de la sociedad. Su libro, Nuevo Cristianismo, publicado en 1825, basaba esta nueva religión en un sentimiento de simpatía y amor universales para cuya promoción rechazaba sin dudarlo al clero del viejo cristianismo y proponía a los artistas como nuevos sacerdotes pensando que estaban mejor dotados para impulsar a la humanidad hacia el progreso mediante la estímulación de los sentimientos. De hecho, mientras originalmente, y bajo su primera y más mecánica filosofía, habia limitado el papel de los artistas a la finalidad positivista de popularizar las ideas introducidas por los hombres de ciencia, ahora, y especialmente en la parte final de sus Opiniones literarias, filosóficas e industriales, también publicadas en 1825, Saint-Simon colocaba a los artistas definitivamente a la cabeza de 
Pues aquí vine con poderes santos y santas facultades ya a trabajar ya a sentir", dice Wordsworth en El Preludio ${ }^{7}$, convencido de que, aunque es un Ser Transitorio, es también el último de un linaje de poetas inspirados por el Espíritu Profético y como tal le ha sido otorgada una Visión.

Con todos ellos nace una concepción nueva, vocacional, temperamental y, desde luego, de genio incomprendido, tan difundida actualmente que incluso hemos olvidado lo reciente de su origen. De hecho, la carrera de la mayoría de los pintores y escultores del siglo XVIII y anteriores la habían determinado principalmente sus familias. Ahora, Runge, Gericault, Delacroix o Constable, van a seguir la llamada del arte incluso con la oposición inicial de su familia y parientes. Su entrada en la comunidad artística iba a tener un efecto rápido y contundente. Aunque muy pocos de ellos gozaban de una real independencia financiera, todos habian heredado precisamente de su ambiente de clase media, una fuerte e incorruptible independencia de espíritu y un desdén por el servilismo que iban a contagiar a los demás artistas para acabar enfrentándose con los clientes privados y con el público en general. Es más, ellos no se dirigían nunca al público globalmente, o a la clase media, en particular. Su arte combativo, que desde luego incitaba explícitamente a la condena, no se dirigía a nadie en concreto. Sólo a quienes fueran capaces de entenderlo, o mejor de sentirlo. $Y$ aunque, como señalan Rosen y Zerner ${ }^{8}$, es cierto que en la crítica del siglo XIX llegó a ser un lugar común el que la primera aparición de una obra de arte levantara el desprecio y la incomprensión general porque todo artista con pretensiones de originalidad esperaba, e incluso deseaba, encontrar cierta resistencia inicial, las consecuencias más o menos secundarias no invalidan la originalidad de una nueva imagen del artista que, más o menos programada, más o menos frivolizada y más o menos aceptada, marcará el resto del siglo salpicando incluso al xx y habrá liberado al arte de unas peligrosas vinculaciones que ya estaban empezando a pesarle demasiado.

Sin embargo, el camino que el artista se ha propuesto no es ni mucho menos fácil. "Más vale renunciar a todas las comodidades, más vale alimentarme y vestirme con la parsimonia que la filosofía más austera autoriza, a fin de conservar la fuerza de llevar a cabo lo que llevo en mi, dar

\footnotetext{
una selecta trinidad administrativa que se componía de artistas, hombres de ciencia e industriales-artesanos.

7 El Preludio, versos 97 y 98.

8 Rosen \& Zerner, Romanticismo y Realismo. Los mitos del arte del siglo XIX, Madrid, Blume, 1988.
} 
vida a estas ideas que nacen y que me he creado en estas dulces horas y que corren el peligro de morir de humana impotencia. Sentirme tan grande y no poder decir: eres todo lo que podías ser, de aquí tu tormento... ¿Por qué este sentimiento infinito en un ser que sólo posee cinco sentidos? ¿Por qué tantos impedimentos frente a la fuerza necesaria para llevar a cabo un empeño? Cuando la tarde, sobre sus alas de oro, lleva a lo lejos mi imaginación, ¿de qué modo no podría sentirme capaz? Pintor, poeta, pensador, todo lo que los rayos de sol despiertan a la vida, todo lo que toma de prestado su llama a la antorcha de Prometeo iquisiera serlo y no puedo! ${ }^{9}$.

A partir de un forzado análisis del grabado Melancolía I de Durero ${ }^{10}$, los románticos forjaron la imagen de un Fausto sombrío, un artista dolido e incapacitado para componer una forma a la altura de sus ideas. Igual que el Hamlet que Schlegel reelabora en su ensayo "Über das Studium der Griechischeb Poesie»: "Una situación extraordinaria concentra todas las fuerzas de su noble alma en el intelecto, aniquilando su capacidad de acción. Su ánimo se desgarra como si la rueda de la fortuna lo hubiese situado ante dos direcciones opuestas; se disgrega y sucumbe en la superabundancia del intelecto inane, que sobre él pesa más de lo que pesa sobre los demás. No se puede representar mejor la irreductible desarmonía que es el auténtico objetivo de la tragedia filosófica, en el sentido de un desequilibrio tan inmenso entre la fuerza del pensamiento y la de la acción, que en el carácter de Hamlet». Un artista que no es un mago, que está muy lejos de ser un mago. Porque Fausto desestimaba los medios que tan sólo podían ayudarle a conocer y explorar mundos ajenos. Él quería fundarlos. Aspiraba a encontrar un arte que le permitiera, no sólo dominar el mundo, sino crear un mundo propio que dependiera exclusivamente de él y sobre el cual tuviera plenos poderes. Aspiraba a la obra de arte total.

La incertidumbre por el futuro del hombre provoca en el arte romántico un último esfuerzo titánico por conjugar, en la obra artística, las dimensiones totalizadoras de las que el mundo, en su existencia cotidiana, se halla privado. No es otro el sentido de «la obra de arte total», el utópico proyecto generado en el entusiasmo cultural del Renacimiento, que el Romanticismo recupera para hacer frente, mediante un voluntarismo estético francamente desmesurado, a su diagnóstico pesimista del futuro. El

9 M. Müller, Fausto, 1778.

10 Ver a este respecto el libro de Klibansky y Panofsky, Saturno y la melancolía, Madrid, Alianza Forma, 1991. 
acercamiento de unas artes a otras, de la poesía a la pintura o a la música, la poesía pictórica y la arquitectura como música congelada, no son más que tentativas o expresiones que denuncian estas aspiraciones. Son muy conocidos ya los intentos de relacionar los colores y las notas musicales, las experiencias anteriores sobre el plano de los colores o las pretensiones de Runge de construir un poema fantástico-musical pictóricamente abstracto, una composición para todas las artes. El ideal de la mezcla es una obra que debería amalgamar y fundir, bajo el signo de la heterogeneidad, todos los géneros, disciplinas artísticas, percepciones de los sentidos y estilos formales; incluso la filosofía o las ciencias naturales. Una obra que supera, sin lugar a dudas, las fuerzas humanas; que se convierte en una tarea infinita, en un ideal.

La imposibilidad de la obra de arte total, soñada por Goethe o por Beethoven y ficticiamente realizada por Wagner, es al mismo tiempo un símbolo de la fecundidad y del fracaso de la rebelión romántica. Del fracaso porque no consiguió modificar el curso de un desarrollo histórico y cultural al que se oponía, pero fecundidad, y en cierto modo triunfo, porque supo suscitar una serie de cuestiones determinadas claramente relacionadas con nuestra cultura actual y de las que somos francos herederos. 